\title{
UMA VACA, UM CHINÊS, UM ARGENTINO E UM “A-CASO"
}

Resenha do filme Um Conto Chinês. Direção: Sebastián Borensztein, 2011, 93 mim, AR.

Maria Claudia Martinelli de Mello Pitrez ${ }^{1}$

Recebido em: Julho, 2013

Aceito em: Novembro, 2013

Para citar esta resenha:

PITREZ, Maria; "Uma vaca, um chinês, um argentino e um "a-caso"" In: Revista

Intratextos, 2013, vol 5, no1, p. $113-121$. DOI:

http://dx.doi.org/10.12957/intratextos.2013.11890

${ }^{1}$ Doutora em Ciências Sociais pelo PPCIS/UERJ cacapitrez@gmail.com. Resenha realizada no curso "Turismos, Migrações, Exílios e as Teorias Contemporâneas da Mobilidade", ministrado por Bianca Freire-Medeiros e Celso Castro, na FGV, 2011. 


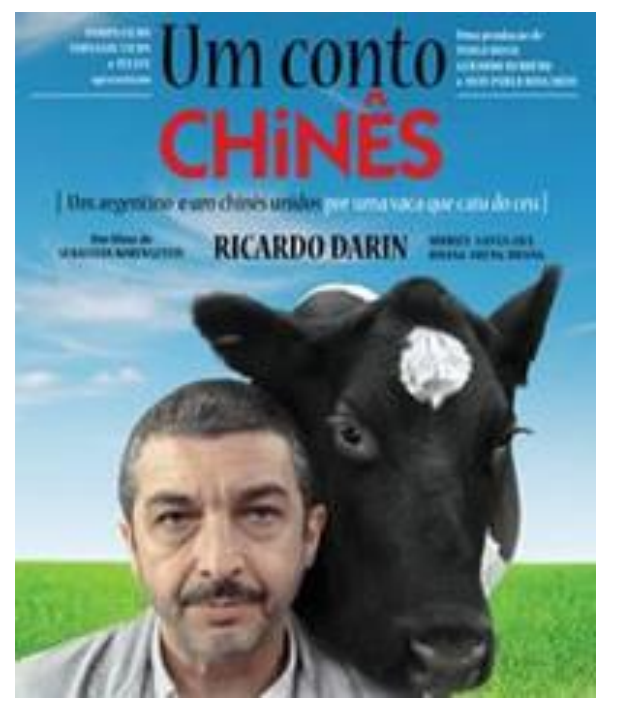

Como um preâmbulo do filme, a primeira cena em plano aberto se assemelha a uma pintura artística, retratando uma paisagem onírica na China. Saindo do panorama entre montanhas, vamos aproximando para o movimento do barco no lago onde encontramos um casal chinês em um romântico passeio. Sem traduções e legendas para o diálogo entre o casal, a cena é cortada inusitadamente com uma vaca caindo do céu em cima da moça, quando seu noivo se afastara para pegar as alianças, restando apenas os destroços do barco e o

desespero do jovem rapaz.

$\mathrm{Na}$ cena seguinte, através do plano sequência que começa de cabeça para baixo, virando lentamente de ponta cabeça, vamos adentrando junto com o movimento da câmera numa loja de ferramentas. Nela descobrimos o personagem principal da trama, conferindo cada parafuso dentro de uma caixa. Com estas duas cenas bastante distintas, fomos rapidamente levados de um lado do "globo" para o outro (daí a ideia da câmera virando de ponta cabeça), saindo de uma situação inusitada que se passava na China rural, para vivenciar um "a-caso" no cotidiano de Roberto, na cidade de Buenos Aires, Argentina.

O filme Un Cuento Chino, dirigido e escrito por Sebastián Borensztein, narra o encontro desses dois personagens apresentados acima: Jun (Ignacio Huang), um jovem chinês que ao perder sua noiva vai à procura do seu tio em Buenos Aires, e Roberto (Ricardo Darín), um homem solteiro e solitário, em torno dos cinquentas anos, que vive metodicamente entre a sua casa e o trabalho na loja de ferramentas que herdou do seu falecido pai. O cruzamento inusitado das vidas de Roberto e Jun é avidamente acompanhado pelo espectador, graças à trama muito bem articulada e à forma cativante de desenvolver o enredo. Sem a pretensão de oferecer uma descrição minuciosa do filme, a presente resenha busca aproximar algumas cenas com questões sociológicas e antropológicas sobre mobilidades, deslocamentos, migração e turismo.

A existência de fluxos cada vez mais intensos na sociabilidade contemporânea, aproximando pessoas de diferentes culturas, é um tema caro na atualidade. Vemos este assunto sendo promovido e debatido nos meios midiáticos, audiovisuais, comerciais, políticos 
e empresariais, como também em diferentes áreas do conhecimento científico. Nas ciências sociais, diferentes autores do final do século XIX, início do XX, já apontavam alguns questionamentos sobre a velocidade e o movimento que a sociedade moderna proporcionava tanto para as transformações sociais, com o crescimento e modernização de cidades, quanto para a vida dos seus cidadãos. Indivíduos "blasé", solitários, aventureiros e estrangeiros são, dentre outros, atores centrais das sociedades modernas trabalhadas pelo sociólogo alemão Georg Simmel (1971a e 1971b). Com devidas reatualizações e me valendo de autores contemporâneos (DAVIS, 2000; ELLIOTT e URRY, 2010; GRABURN, 1989; KAPLEN, 1998; NUÑEZ, 1989; e SMITH, 1989), considero valiosas as contribuições de Simmel para refletir sobre a dinâmica entre situações ordinária e extraordinária, e os diferentes papéis identitários (aventureiro e estrangeiro) vivenciados pelos personagens do filme.

A partir do jogo de contrastes provocado por este encontro entre alteridades argentina e chinesa - e das discussões desenvolvidas pelo campo das ciências sociais sobre deslocamentos e trocas culturais, gostaria de chamar a atenção para alguns pontos: 1) aproximação e distanciamento na comunicação entre "desconhecidos"; 2) rotina e momentos de ruptura/ ordinário e extraordinário; e 3) as mudanças na vida dos personagens após o ocorrido "a-caso".

\section{Aproximação e distanciamento na comunicação entre "desconhecidos"}

Um dos primeiros choques culturais que fica logo perceptível ocorre na comunicação. Não há uma língua comum que seja compreendida por ambos os personagens. Jun não fala e tampouco compreende espanhol, assim como Roberto não sabe nada de chinês e nem se quer imagina que há dialetos distintos falados na China. Fato que se evidencia quando Roberto procura o bairro chinês em Buenos Aires para conseguir um tradutor e percebe que nem os dois chineses, colocados um em frente ao outro, estavam se compreendendo. Esta troca sem comunicação verbal também é vivenciada pelos espectadores, uma vez que apenas a fala chinesa não é legendada. Somos convidados, portanto, a compactuar com o personagem argentino, sem entender uma palavra que é falada pelo estrangeiro chinês em Buenos Aires.

Outro exemplo bastante explorado no filme é o momento da alimentação. Sem hábitos comuns e sem comunicação verbal, há cenas em que o argentino apresenta comidas típicas, 
como o chorizo e a criadilla, sem que o chinês entenda qualquer palavra e a tradição destes pratos; e outras em que o estrangeiro busca copiar os hábitos alimentares do seu anfitrião. Ao mesmo tempo em que a alimentação explicita um estranhamento, ela também revela aproximações. No caso do filme, as refeições tornam-se um momento importante para estabelecer uma relação próxima entre os personagens que, sentados à mesa, ficam um de frente para o outro. Como argumenta Simmel (2004), as refeições têm uma função sociológica que é a de conciliar um ato individual e fisiológico de ingestão de alimento com costumes e tradições coletivas. "O incomensurável significado sociológico da refeição está contido na possibilidade de pessoas que não partilham interesses específicos se encontrarem para uma refeição em comum" (2004: 2). É justamente em um destes momentos que Roberto consegue encontrar um mediador para traduzir suas angustias e aflições provocadas pelo estrangeiro não convidado em sua casa. Através de um entregador de comida chinesa, que é filho de imigrantes chineses, finalmente a comunicação verbal é feita, e ambos puderam conhecer um pouco mais o outro, aproximando e distanciando suas histórias de vida.

Sem ser um viajante convidado, de lazer ou a trabalho, o deslocamento do jovem chinês para a Argentina não passa por mediadores que possam facilitar a sua entrada no "novo" mundo, especialmente em relação à língua e a determinados comportamentos culturais. Com a entrada acidental de Jun na vida de Roberto, percebe-se como o processo de comunicação entre os dois personagens vai se desenvolvendo por meio de diferentes formas criativas, que perpassam por gesticulações, desenhos, olhares e expressões de sentimentos. Aqui, podemos pensar nas ideias trazidas por Nuñez (1989) sobre a importância do mediador para atenuar os desafios provocados por estes encontros entre os "de fora" e "de dentro". Para Nuñez, os desconfortos e mal entendidos oriundos do encontro entre diferentes contribui para a criação de novos papéis sociais voltados para a interlocução das distâncias socioculturais. No caso do filme, esta mediação por terceiros não é tão evidente, exceto através do entregador de comida chinesa, e aproximação das distâncias ocorre através de iniciativas criativas e de negociações entre os dois personagens.

Como fica claro na trama, a relação entre o chinês e o argentino se inicia de forma tensa, tanto pelo acaso em que se deu o encontro entre eles, quanto pela falta de comunicação verbal. Na primeira noite de Jun na casa do Roberto, este o tranca no quarto e faz um quadro com os números de 1 a 7 , correspondendo aos dias que poderá ficar abrigado até encontrar o 
tio chinês desaparecido. Todavia, ao longo do filme a indiferença vai dando lugar ao envolvimento e esta situação tensa vai ganhando outro tom com atitudes de cumplicidade e reciprocidade, aproximando os dois "des-conhecidos".

\section{Rotina e rupturas/ ordinário e extraordinário}

Com diferentes cenas consecutivamente filmadas em ambientes fechados, vamos conhecendo o personagem argentino. Como um típico homem solitário e mal humorado, Roberto evita qualquer contato, trocando apenas o necessário com os seus poucos clientes e fornecedores. Ele vive enclausurado na loja e na sua casa, que fazem parte da mesma edificação, separada apenas por cômodos distintos que se conectam internamente. Para completar, o personagem é cheio de manias: fixação por números, que fica expressa na obsessiva contagem de cada parafuso, conferindo cada caixa entregue pelo fornecedor; precisão e repetição na hora que vai dormir todos os dias; e o hábito rotineiro de colecionar notícias inusitadas e objetos decorativos de diferentes lugares do mundo.

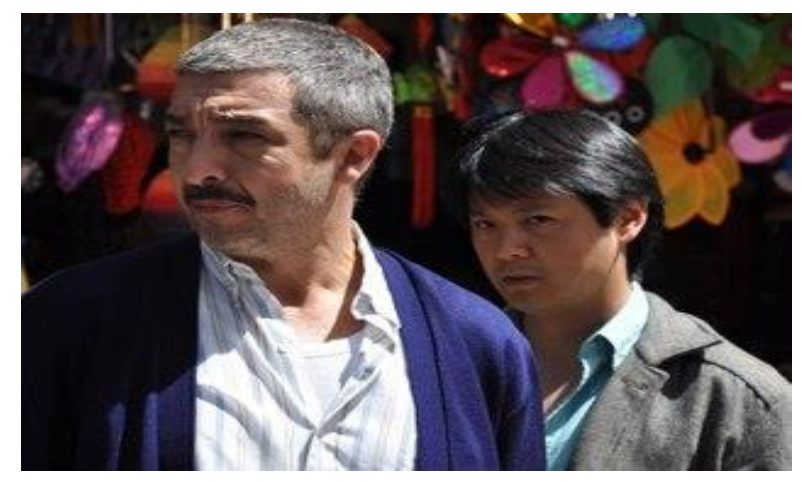

Sem se aventurar e vivendo de forma isolada, como um estrangeiro no seu próprio meio social, a vida de Roberto transcorre metodicamente a cada dia. Por sua vez, temos o chinês que está vivendo justamente o contrário ao seu anfitrião, está em deslocamento, rompendo com a rotina, fora da sua vida normal e da sua cidade. Há uma tensão clara nesta relação entre o cotidiano ordinário e o extraordinário que vai se desenrolando com o encontro entre os dois personagens a partir de uma dada situação: a cena de Jun sendo brutalmente expulso pelo taxista na rua em frente ao local em que estava Roberto, num raro momento de lazer, bebendo, ouvindo musica e vendo os fluxos de aviões. Ao socorrer o estrangeiro e abrigando-o na sua casa a contragosto, a rotina de Roberto vai sendo pouco a pouco 
transformada com o seu novo "convidado".

Jun que, no início era apenas um incômodo, começa a ajudar na arrumação da casa do Roberto, a mando do anfitrião. Desde que voltou dos campos de batalha da Guerra das Malvinas e encontrou seu pai morto em casa, Roberto estabeleceu uma vida sistemática e metódica entre casa e trabalho, não alterando nada na arrumação nem da casa, nem da loja. Com objetos e móveis velhos, a casa parece parada no tempo. A área externa, que era um local de entulhos, foi paulatinamente se transformando, ficou arrumada com paredes pintadas pelo chinês que trabalhava com artesanato e desenhos na sua terra de origem.

Estando em trânsito, viajando para rever um passado sentimental, um familiar distante, o jovem chinês estrangeiro está em uma situação ambígua. A condição liminar, extraordinária e de um "entre-lugar", tal como descrevem Graburn (1989) e Davis (2000), envolve muita insegurança, desconfiança e desconforto. Como observa Simmel (1971), nas relações com a pessoa estrangeira, existem tipos de situações e elementos que provocam um distanciamento e contribuem para produzir um modelo de interação pautado por relações estereotipadas, desconfiadas ou mesmo preconceituosas.

$\mathrm{Na}$ trama, estas relações ficam explícitas durante as cenas entre o jovem chinês e o Roberto, além de certos momentos em que Jun sofre uma série de constrangimentos, ao ser confundido como um imigrante ilegal em busca de melhores condições de vida e trabalho na Argentina. Um taxista que o expulsa do carro; um policial que fala para Roberto deixá-lo na delegacia detido; e um cliente do Roberto que fala para ele legalizar o chinês.

Roberto é um colecionador de lugares, mas nunca viajou para eles. Ele está preso a uma rotina, a lembranças do pai com quem conviveu e da mãe que nunca a conheceu. Não se permite ir e vir livremente para descobrir novos ares e novas experiências, nem se entregar ao amor de Maria (Mueriel Santa Ana), que não mora na mesma cidade é apaixonada por ele. Sem internet e outros meios tecnológicos que o possibilitam ir "além da vizinhança" (ELLIOTT e URRY, 2010), ele conta com a ajuda de um amigo vizinho para encomendar souvenirs e jornais do mundo. Nos momentos de relaxamento, ele recorta dos jornais histórias sobre situações e acidentes inusitados, mania que acaba sendo um contraponto à vida sistemática do personagem argentino. Uma forma de quebrar o controle da rotina e o pragmatismo em que vive através de fatos de outros lugares, especialmente àqueles que fazem 
a vida não ter sentido, como a vaca que é lançada de um avião, após ter sido roubada por ladrões de uma vila rural da China, caindo sob a cabeça de uma mulher no barco, que estava a passeio ao lado do seu noivo.

\section{Mudanças na vida dos personagens após o "a-caso"}

Assim como a trama mostra a diferenciação entre a vida sistematizada e controlada de Roberto com o momento de ruptura e limiar que Jun vive em outro país, para muitos autores este tema entre o ordinário e o extraordinário torna-se central ao se trabalhar com questões sobre deslocamentos, turismo, viagens, lazer e rituais (DAVIS, 2000; ELLIOTT e URRY, 2010; GRABURN, 1989; KAPLEN, 1998; NUÑEZ, 1989; SMITH, 1989 e SIMMEL 1971a e 1971b). Diante desta perspectiva teórica, a vida está organizada com pausas estruturalmente programadas para embelezar e aliviar a rotina maçante, através de uma sucessão de períodos compreendidos entre o ordinário, caracterizado pela rotina e pelo trabalho compulsório, e o extraordinário, que compreende os momentos de passagem, de romper, de viajar, de estar fora de casa. Todavia, ambos os momentos estão correlacionados e seus aspectos contrastantes desempenham diferentes funções para cada parte (GRABURN, 1989; SIMITH, 1989; SIMMEL, 1971a e 1971b).

Para Graburn (1989), esta demarcação temporal traz implicações morais e simbólicas para a vida de cada sujeito social. As datas e os calendários não têm apenas a função de orientar e numerar a vida das pessoas, mas também de provocar emoções, sensações e deslocamentos que são essenciais à vida moderna. Cada deslocamento promove uma espécie de "rito de passagem" onde o indivíduo, após finalizá-lo, se transforma e se reintegra socialmente com um novo estado de espírito.

Para retornar ao título desta resenha, o que uma vaca, um chinês e um argentino têm em comum? Como vimos na descrição da primeira cena do filme, a queda da vaca em cima da noiva de Jun é um dos motivos que o propulsiona a se aventurar e a buscar o seu tio em terras estrangeiras. Este fato só vai ser ligado com a história de Roberto nas últimas cenas através do segundo encontro com o mediador verbal, o entregador de comida chinesa. Ao ser interrogado sobre a estranha mania de colecionar pedaços de jornais, Roberto responde que um dos seus passatempos é juntar histórias reais que tenham um tom surreal. Ao ler a reportagem do caso 
da vaca para Jun e este, tristemente, confirmar o "a-caso" com a sua história de vida, somo levados ao encontro máximo entre o ordinário e o extraordinário.

Até que ponto o encontro com a alteridade traz modificações para as nossas vidas? Sem precisar uma resposta aqui, podemos ver no filme uma boa dose de transformação que cada personagem vivenciou diante do convívio próximo e distante com o outro. Jun, de luto e distante dos seus entes e da sua cultura, pôde encontrar solidariedade e reciprocidade de pessoas estranhas, o que lhe permitiu um processo de fortalecimento para regressar ao seu país e convívio social.

No caso de Roberto vemos uma transformação que também lhe provocou uma nova inserção social. Como um estrangeiro em seu próprio universo social, Roberto só se aproximava do seu desejo nos momentos em que estava sozinho em casa. Fantasiando as histórias que lia no jornal e substituindo os personagens por ele e Maria, Roberto sonhava com o seu amor enrustido. Através da história de Jun, a vida de Roberto se transforma não apenas no que se refere às atividades e tarefas diárias, mas sobretudo em relação ao seu espírito. Ao ver Jun viajando para um lugar diferente e distante da sua terra em busca de um reencontro com seu tio e consigo próprio, Roberto reavalia seu cotidiano. Só conseguimos novos ares, coloração, emoção e intensidade à vida quando cruzamos as fronteiras entre o ordinário e o extraordinário (GRABURN, 1989) e nos aventuramos (SIMMEL, 1971), tal como fez Roberto ao encontrar Maria na sua casa de campo, no interior da Argentina, sentada ao lado da sua vaca.

Histórias de vida bastante divergentes entre si e cada qual de uma parte do globo, mostram tensões, indiferenças, afinidades e complementaridades ao serem topadas e cruzadas de forma casual. A sensação de viver buscando sentido a partir do controle se choca ao encontrar um "outro" aparentemente estranho, sem sentido e forasteiro. Percebe-se na trama como esta relação pode ser comunicável e também apresentar muitas semelhanças entre si. O que começou de forma trágica, por causa de uma vaca, termina também com a vaca compondo o cenário final, mas agora diante do personagem argentino que, de espírito renovado, se aventura em busca do seu desejo.

\section{Referências Bibliográficas:}


DAVIS, D. To be or not to be Brazilian? Carmen Miranda's quest for fame and "authenticity". IN: The United States. Strange Pilgrimages: exile, travel and national identity in Latin America, 18001900s. p. 233- 248, 2000.

ELLIOT, E. \& URRY, J. Mobile Lives. London, NY: Routledge, 2010.

GRABURN, N. Tourism: The Sacred Journey. IN: Smith V. L. (ed.), Hosts and Guests: The Anthropology of Tourism. Second edition. The University of Pennsylvania Press. p. 2236, 1989.

KAPLAN, C. Questions of Travel: Postmodern discourses of displacement. Durham/London: Duke University Press, 1998.

NUÑEZ, T. Touristic studies in anthropological perspective. IN: Smith V. L. (ed.), Hosts and Guests: The Anthropology of Tourism. Second edition. The University of Pennsylvania Press, p. 265-279, 1989.

SMITH, V. Introduction. In Smith V. L. (ed.), Hosts and Guests: The Anthropology of Tourism. Second edition. The University of Pennsylvania Press.p. 1-17, 1989.

SIMMEL, G. The stranger. On individuality and social forms. Selected writings. Levine, Donald (ed). Chicago/Londres: The Univerisity of Chicago Press, 1971. The adventurer. On individuality and social forms. Selected writings. Levine, Donald (ed). Chicago/Londres: The Univerisity of Chicago Press, 1971. IN: Estudos Históricos, Rio de Janeiro: CPDOC/FGV, nº 33, 2004.

URRY, J. Mobilities. London: Polity, 2007. 